\title{
BIODIVERSITAS IKAN DI REFUGE AREA SUNGAI KAPAS TENGAH HUTAN HARAPAN JAMBI SEBAGAI DATABASE APLIKASI GO IWAK
}

\author{
Fish Biodiversity in Refuge Area Sungai Kapas Tengah Hutan \\ Harapan Jambi as Go Iwak Aplication Database \\ TEDJO SUKMONO', WAWAN KURNIAWAN ${ }^{2}$, TIA WULANDARI \\ 'Biologi FST Universitas Jambi \\ 2Fisika FKIP Universitas Jambi
}

\section{Email: tedjo sukmono@unja.ac.id}

\begin{abstract}
Penelitian ini bertujuan untuk mengetahui biodivesitas ikan di Refuge area Sungai Kapas bagian Tengah Hutan Harapan Jambi. Penelitian telah dilakukan pada Juli-Agustus 2019 di Sungai Kapas Hutan Harapan Jambi. Penentuan refuge area dilakukan dengan menyusuri Sungai Kapas bagian tengah untuk menemukan anak-anak sungai yang sudah terputus dengan Sungai kapas, serta bagian sungai kapas serta areal lubuk di Sungai Kapas. Terdapat 4 Refufe area yang dijadikan stasiun yaitu Stasiun 1 Putusan Marihot, Stasin dua Muara Bato, Stasiun 3 Lubuk Kapas, dan Stasiun 4 Lubuk Bato. Pengambilan sampel menggunakan jala lempar , seruo, dan jaring insang, serta tray net. Hasil Penelitian didapatkan 375 ekor ikan, melputi 50 spesies, 29 genus, dan 14 famili, serta 6 ordo. Pada stasiun 2 (Putusan Marihot) ditemukan paling banyak jumlah ikan 151 ekor, diiukuti stasin 3 (Lubuk Kapas) 111 ekor, stasiun 3 (Muara Bato) 71 ekor dan Stasiun 4 ( Lubuk Bato ) 42 ekor. Jumlah spesies setiap stasiun 1 (8 spesies), Stasiun 2 (16 spesies), (29 spesies), stasiun 4( 18 spesies).
\end{abstract}

Kata Kunci : Refuge area, Biodiversitas, Hutan Harapan

\begin{abstract}
Abstrak This study aims to determine the biodiversity of fish in the refuge area of Sungai Kapas in the middle of the Hutan Harapan, Jambi. The study was conducted in July-August 2019 in Sungai Kapas, Hutan Harapan, Jambi. The determination of the refuge area is carried out by going along the middle Sungai Kapas to find the tributaries that have been cut off by the Sungai Kapas, as well as the Sungai Kapas section and the deep area of the Kapas River. There are 4 Refufe areas that are used as stations, namely Marihot Putusan first station, Muara Bato second station, Lubuk Kapas third station, and Lubuk Bato fourth station. Sampling using throwing nets, seruo, and gill nets, and tray net. The results showed 375 fish, covering 50 species, 29 genera, and 14 families, and 6 orders. At station 2 (Marihot's verdict) the highest number of fish was 151 fish, followed by stasin 3 (Lubuk Kapas) 111 fish, station 3 (Muara Bato) 71 fish and Station 4 (Lubuk Bato) 42 fish. Number of species per station 1 (8 species), Station 2 (16 species), (29 species), station 4 (18 species).
\end{abstract}

Keywords : Refuge area, Biodiversity, Hutan Harapan 


\section{INTRODUCTION}

Hutan Harapan merupakan kawasan restorasi ekosistem pada areal hutan hujan tropis dataran rendah pertama di Indonesia. Arealnya merupakan bekas wilayah hak pengusahaan hutan $(\mathrm{HPH}$, terletak antara Propinsi Jambi dan Sumatra Selatan dengan luas $\pm 100.000 \mathrm{Ha}$ (REKI 2008).. Menurut Sukmono et al. (2013) sedikitnya terdapat 15 ekosistem perairan di Hutan Harapan terdiri atas: sungai besar yang berarus lemah bersifat banjiran, danau ataupun rawa, berpotensi memiliki keanakaragaman ikan air tawar tinggi. Kenakergaman ikan di Hutan Harapan tercatat 123 species meliputi , 62 genus dan 23 famili (Sukmono et al 2013). Keanekaragaman ikan yang timggi di Hutan Harapan berpotensi di jadikan model studi untuk penegmbangan metode identifikasi ikan berdasarkan morofologi, molecular maupun berbasis aplikasi (teknobiodiversity).

Meneurut Kottelat et al 1993., identifikasi spesies ikan yang cepat dan akurat merupakan komponen penting dalam pemantauan dan konservasi keanekaragaman hayati dalam skala global, umumnya masih dilakukan secara morfologi (morfometri dan meristik), namun dalam perkembangannya karakter morfologi memiliki kesulitan dan keterbatasan terutama ketersediaan buku-buku identifikasi dan ternbatasnya ahli taksomomi ikan sebagai termpat konfirmasi. Identifikasi motfologi juga membutuhkan waktu yang lama karena perlu menghitung semua karakter morfometrik dan merisitik ikan sebelum dicocokan dengan kunci determinasi, serta harus dilakukan oleh ahli taksnomi ikan.

Keberadaan ikan dalam suatu areal sangat dipengaruhi oleh musim kemarau dan penghujan. Karakter sungai di Hutan Harapan merupakan sungai banjiran pada saat kemarau sangat kering dan terdapat beberapa anak sungai yang terpisah dengan sungai utama. Pada saat penghujan banyak ditemukan dataran banjiran dan sungai yang terpisah menyatu kembali dengan sungai utama (Sukmono 2013) Pada musim kemarau umumnya ikan bertahan di refuge area berupa putusan sungai maupun lubuk yang tetap berisi air di anak sungai. Keberadaan refuge area menjadi sangat penting untuk mempertahankan biodiversitas ikan di Sungai Kapas Hutan Harapam. Adapun tujuan penelitian ini adalah untuk mengetahui biodibversitas dan distribusi ikan di Refuge area yang berada di Sungai Kapas Tengah Hutan harapan Jambi.

\section{MATERIAL AND METHODE}

Penelitian dilakukan pada Juli-Agustus 2019 di Sungai Kapas Hutan Harapan Jambi. Penentuan refuge area dilakukan dengan menyusuri Sungai Kapas bagian tengah untuk menemukan anak-anak sungai yang sudah terputus dengan Sungai kapas,, serta bagian sungai kapas serta areal lubuk di Sungai Kapas. Terdapat 4 Refufe area yang dijadikan stasiun yaitu Stasiun 1 Putusan Marihot, Stasin dua Muara Bato, Stasiun 3 Lubuk Kapas, dan Stasiun 4 Lubuk Bato.

Pengambilan sampel ikan dilakukan menggunakan gillnet (jarring insang) ukuran mesh 0.5, dan 1 inch, serta jala lempar ukuran mesh 0,5 inc dan Tray net. Pada saat survai kondisi sungai snagat kering dan dangkal , sehingga jaring dipasang melintang pada Lubuk sungai kapas. Pemasangan jarring dilakukan mulai pukul 08.00-16.00 dan sampel yang tertangkap diangkat 3 jam sekali. Tray net digunakan untuk menangkap ikan di lubuk sungai yang sempit dan dangkal. Jala lempar digunakan pada areal putusan sungai dan lubuk yang relative luas dan tidak banyak rebahan kayu. Sampel ikan yang tertangkap dalam keadaan hidup akan dimasukkan dalam aquarium mini denagn aqua scape dan ditambahkan beberapa tetes minyak cengkeh untuk memberikan efek lemas, selanjutnya difoto hidup dalam aquarium.

Sampel ikan yang mati difioto dalam keadaan segar dengan kepala menghadap kekiri, dan sirip direntangkan dengan latar warna merah atau hitam dan ditambah skala. Identifikasi cepat dilakukan di Camp Bato bedasarkan 15 karakter morfometrik dan 7 karakter meristik. Hasil foto Sampel hidup maupunmati selanjutnya digunakan untuk penyusunan aplikasi digital identifikasi " Go Iwak “.

\section{RESULT AND DISCUSSION Gambaran Lokasi Penelitian}

Penentuan stasiun peneliiian dilakukan secara purposive sampling berdasarkan tiplogi habitat. Keberadaan refuge area ditemukan dengan menjelajah menyusri sungai kapas dan sungai Bato untuk menemukan areal sungai yang masih banyak genangan air dan diduga sebagai habitat ikan saat musim kemaraau. Keberadaan refuge area saat musim kemarau menjadi sangat penting karena merupakan air tempat berkumpulnya ikan terhadap kekeringan. Terdapat 4 Refuge area yang 
dijadikan stasiun peneltian yaitu Stasiun 1 (Muara Bato) , Stasin2(Putusan Marihot), Stasiun 3 (Lubuk Kapas), dan Stasiun 4(Lubuk Bato). Gambaran stasiun penelitina disajikan pada Gambar 1.
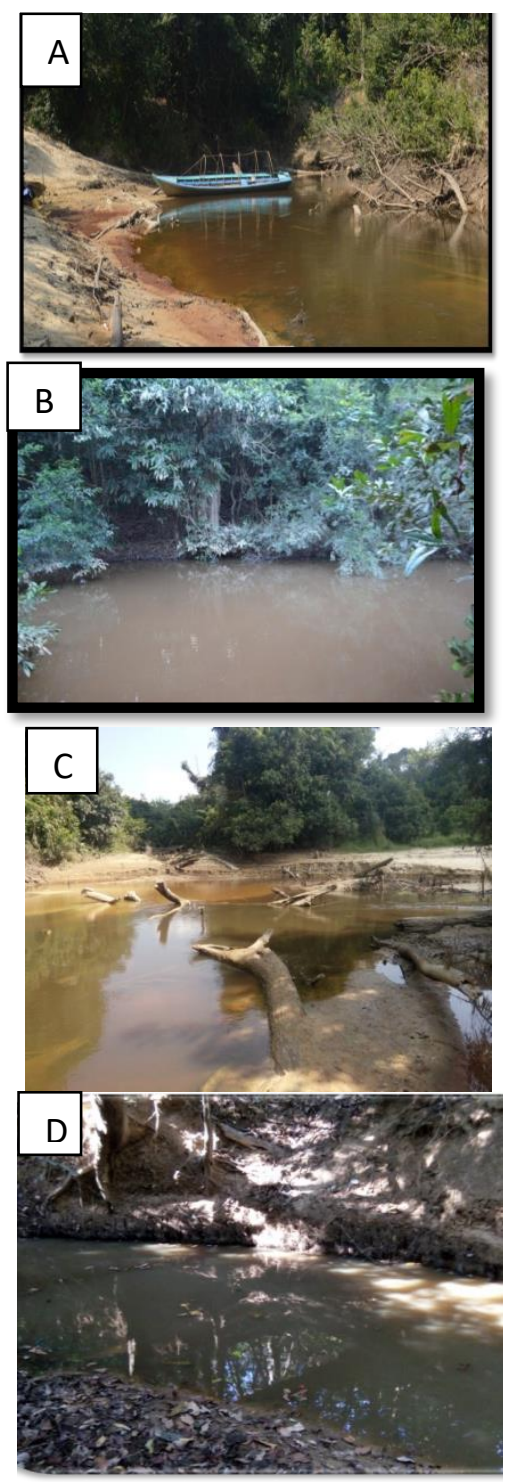

Gambar 1. Refuge area Sungai Kapas Tengah; A) Muara Bato, B) Putusan Marihot, C) Lubuk Bato, D) Lunuk Kapas Tengah

Kondis setiap Refuge area dapat digambarkan sebagai berikut:

\section{Stasiun Muarao Bato Bato}

Merupakan muara pertemuan anatara Sungai Kapas dan Sungai Bato berada pada posisi koordinat $2^{\circ} 14.15$ South $1,3^{\circ} 17^{\prime} 20.5$ East. Warna air kecoklatan. Subtract dasar pasir campur serasah serta banyak bermunculan batang kayu mati. Kondisi vegetasi tepian sungai berupa rotan (calamus $s p$ ) dan seduduk (Melostomia sp). Morfometri sungai Lebar 26,9 m dan lebar aliran $14.1 \mathrm{~m}$, kedalaman 1.6 $\mathrm{m}$, kecerahan $73 \mathrm{~cm}$. kecepatan arus 0.35 $\mathrm{m} /$ detik, suhu $27^{\circ} \mathrm{C}$ dan $\mathrm{pH} 4.5$.

\section{Stasiun Putusan Marihot}

Merapakan bekas aliran Sungai Kapas yang terputus karena kemarau. Bebrntuk tapal kuda dengan bagian inlet dan outlet bertemu dengan Sungai Kapas. Berbentuk tapal kuda dengan panjang sekitar $500 \mathrm{~m}$. Putusan Marihot berada pada posisi koordinat $02^{\circ} 14.15$ South dan 103,17'20.5 East. Air berwarna coklat pekat dengan dasar lumpur dan pasir. Kanopi sekitar Putusan masih rapat nampak bekas lumpur di daun daun pohon pada ketinggian 3-5 m, Menunjukkan jika banjir ketinggian air hingga mencapai $5 \mathrm{~m}$., lebara aliran $20 \mathrm{~m}$, kedalaman $50 \mathrm{~cm}$, Suhu $27^{\circ} \mathrm{C}, \mathrm{pH} 4.5$

\section{Lubuk Kapas Tengah}

Merupakan area yang masih dalam di Sungai Kapas pada saat musim kemarau panjang tahun 2019 , berada pada koordinat $02^{\circ} 14.860^{\prime}$ South dan $103^{\circ} 17^{\prime} 224$ East. Warna air kecoklatan dengan subrtat dasar pasir campur serasah daun, Morfometri sungai lebar $29 \mathrm{~m}$. lebar aliran $16 \mathrm{~m}$. kedalaman $1.4 \mathrm{~m}$. Kecepatan arus 0/15 m/detik, kecerahan $77 \mathrm{~cm}$, suhu $270 \mathrm{C}$, dan pH 5 .

\section{Lubuk Sungai Bato}

Pada musim kemarau kondoi sungai kering denga menyusri sungai baru bisa ditemukan beberpa areal sungai yang masih berair. Lubuk Sungai Bato berada sekktar $500 \mathrm{~m}$ dari Muara Sungai Bato. Vegetasi sekitar masih rapatt berupa hutan sekunder dan di sempadan Sungai masih banyak ditemukan pohon besar dari jenis Meranti dan karet. Lubuk Sungai Bato berada pada koordinat $02^{\circ} 14.52$ South , 103,17’25,.7 East. Morfometro sungai lebar $6 \mathrm{~m}$, da leabra aliran $2.5 \mathrm{~m}$. Warna air coklat dasar lumpur dan serasah. kedalaman $40 \mathrm{~cm}$.

Berdasarkan hasil penelitian sukmono dkk , 2013 Sungai kapas memiliki karakter sebagai sungai banjiran dengan cirri utama memiliki banyak anak sungai dan rawa-rawa sekitar sungai, saat musim hujan banyak sekali terbentuk dataran banjir dan saat musim kemarau beberapa anak sungai akan terpisah dengan sungai uatama menbentuk oxbow, dan pada dataran banjir akan ditemukan rawa-rawa berupa genangan air. Sungai utama akan mongering namun tidak sampai habis dan beberapa tempat sangat dangkal, namun 


\section{T. SUKMONO, W. KURNIAWAN DAN T. WULANDARI}

sebagian lagi tetap dalam (;ubuk). Saat musim kemarau oxbow dan rawa-rawa, serta lubuk tersebut punya peran penting sebagai tempat berkumpulnya biodiversitas ikan di Sungai Kapas 9refuge area). Stasiun pada peneliitian ini merupakan refuge area yang ditemukan di Sungai Kapas bagian tengah.

\section{Biodiversitas Ikan di Refuge Area Sungai Kapas Tengah}

Selama penelitian di areal Sungai Kapas didapatkan 375 ekor ikan, melputi 50 spesies, 29 genus, dan 14 famili, serta 6 ordo. Enam Famili dengan jumlah sepeseis terbanyak meliputi; Cyprinidae (29 spesies), Siluridae (4 spesies), Bagridae (3 speseis) dan Nemachelidae dan Zenatchopteridae masingmasing 2 spesies. Daftar famlii, dan spesies ikan di refuge area Sungai Kapas disajikan pada talel 1 .

Tabel 1 Daftar family, dan spesies ikan di refuge areadi Sungai Kapas Tengah hutam harapan

\begin{tabular}{|c|c|c|c|}
\hline No & Family & Spesies & NamaLokal \\
\hline \multirow[t]{3}{*}{1} & Bagridae & Mystusmicracantus & biran \\
\hline & & Mystusnemurus & baungrambai \\
\hline & & Mystusnigriceps & keting, berngit, senggiring \\
\hline \multirow[t]{2}{*}{2} & Channidae & Channastriata & Ruan, Gabus \\
\hline & & Channamicropeltes & Toman \\
\hline \multirow[t]{19}{*}{3} & Cyprinidae & Barbodeslateristriga & Kepyur \\
\hline & & Barbonymusschwanenfaldii & Lampam \\
\hline & & Cyclocheilichthysapogon & Kopras \\
\hline & & Cyclocheilichthysarmatus & Kopras \\
\hline & & Cyclocheilichthysenoplos & Kopras \\
\hline & & Cyclocheilichthysheteronema & Kopras \\
\hline & & Labiobarbusfestivus & Terpayang \\
\hline & & Labiobarbusocellatus & Terpayang \\
\hline & & Luciosomatrinema & seluangjuo \\
\hline & & Macrochirichthysmacrochirus & parang-parangbengkok \\
\hline & & Malayochelamaassi & seluangpipih \\
\hline & & Osteochiluskappeni & aropadi \\
\hline & & Osteochilusmelanopleura & Kujam \\
\hline & & Osteochilusspirulus & Kujam \\
\hline & & Osteochilustriporos & Kujam \\
\hline & & Osteochiluswandersii & Kujam \\
\hline & & Oxygasteranomalura & Seluang ping-ping \\
\hline & & Parachelahypopthalmus & amis-amis \\
\hline & & Parachelaoxygastroides & amis-amis \\
\hline
\end{tabular}


BIODIVERSITAS IKAN DI REFUGE AREA SUNGAI KAPAS TENGAH HUTAN

HARAPAN JAMBI SEBAGAI DATABASE APLIKASI GO IWAK

\begin{tabular}{|c|c|c|c|}
\hline & & Puntigrustetrazona & aji-aji \\
\hline & & Puntiuslineatus & seluangkuring \\
\hline & & Rasborabankanensis & Seluang \\
\hline & & Rasboracaudimaculata & Seluang \\
\hline & & Rasbora cf. sumatrana & Seluang \\
\hline & & Rasboradusonensis & Seluang \\
\hline & & Rasboraelegans & Seluang \\
\hline & & Rasborasumatrana & Seluang \\
\hline & & Rasboratrilineata & Seluang \\
\hline & & Thynnichthysthynnoides & Damaian \\
\hline 4 & Eleotridae & Oxyeleotrismarmorata & Betutu \\
\hline 5 & Helostomatidae & Helostoma temminckii & Tembakang \\
\hline 6 & Mastacembellidae & Mastacembeluserythrotaenia & tilanapi \\
\hline 7 & Nandidae & Nandusnebulosus & kerapurawa \\
\hline 8 & Nemacheilidae & Nemacheilusfasciatus & Tali-tali \\
\hline & & Nemacheiluskapuasensis & Tali - tali \\
\hline 9 & Osphronemidae & Trichopodusleerii & sepat \\
\hline 10 & Pristolepididae & Pristolepisgrootii & Sepatung \\
\hline 11 & Schilbidae & Pseudeutropiusmoolenburghae & riu-riu \\
\hline 12 & Siluridae & Kryptopteruslimpok & lais \\
\hline & & Kryptopterusmacrocephalus & lais \\
\hline & & Kryptopterus sp. & lais \\
\hline & & Ompokeugeneiatus & laisbengkok \\
\hline 13 & Syngnathidae & Hippichthysspicifer & tangkur \\
\hline 14 & Zenarchopteridae & Hemirhamphodontengah & julung-julung \\
\hline & & Zenarchopterusdispar & julung-julung \\
\hline
\end{tabular}


Daftar jumkah spesies tiap family disajikan pada Tabel 2

Tabel 2 Daftar jumlah spesies dalam setiap Famili

\begin{tabular}{lll}
\hline No & Famili & JumlahSpesies \\
\hline 1 & Cyprinidae & 29 \\
2 & Bagridae & 3 \\
3 & Channidae & 2 \\
4 & Eleotridae & 1 \\
5 & Helostomatidae & 1 \\
6 & Mastacembellidae & 1 \\
7 & Nandidae & 1 \\
8 & Nemacheilidae & 2 \\
9 & Osphronemidae & 1 \\
10 & Pristolepididae & 1 \\
11 & Schilbidae & 1 \\
12 & Siluridae & 4 \\
13 & Syngnathidae & 1 \\
14 & Zenarchopteridae & 2 \\
\hline
\end{tabular}

\section{FAMILI DENGAN JUMLAH SPESIES...}

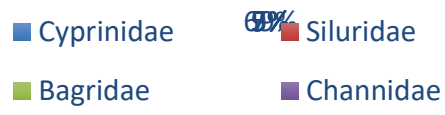

Gambar 2. Enam famili dengan jumlah spesies terbanyak

Famili Cypriniade mendominasi hingga $80 \%$, dominasi ini lebih besar dibandingkan secara keseluruhan ikan Hutan Harapan family Cyprinifae 66\% (sukmono 2013). Menurut Rahardjo dkk, 2011 ikan di Jawa dan Kalkmantan juga didominasi oleh family Cypriniade. Keanekaragaman ikan di Sungai Batanghari juga didominasi oleh family Cyprinidae ( Kotelat et al 2009 ). Keberdaan setiap spesies di Refuge area tidak tersebar merata, distribusi hasil tangkapan per stasiun disajikan pada Tabel 3.

Tabel 3. Distribusi keberadan ikan di refuge area Sungai Kapas Tengah

\begin{tabular}{|c|c|c|c|c|c|c|}
\hline Spesies & NamaLokal & St1 & St2 & St3 & St4 & Jumlah \\
\hline Mystusmicracantus & biran & - & - & 1 & - & 1 \\
\hline Mystusnemurus & baungrambai & - & - & 1 & - & 1 \\
\hline Mystusnigriceps & keting, berngit, senggiring & - & - & 2 & - & 2 \\
\hline Channastriata & Ruan, Gabus & - & - & 1 & - & 1 \\
\hline Channamicropeltes & Toman & - & - & - & - & 0 \\
\hline Barbodeslateristriga & Kepyur & - & - & 2 & - & 2 \\
\hline Barbonymusschwanenfaldii & Lampam & - & - & 2 & 1 & 3 \\
\hline Cyclocheilichthysapogon & Kopras & - & 4 & 5 & 1 & 10 \\
\hline Cyclocheilichthysarmatus & Kopras & - & 14 & - & - & 14 \\
\hline Cyclocheilichthysenoplos & Kopras & - & - & 14 & - & 14 \\
\hline Cyclocheilichthysheteronema & Kopras & - & 3 & - & - & 3 \\
\hline Labiobarbusfestivus & Terpayang & 1 & & - & - & 1 \\
\hline Labiobarbusocellatus & Terpayang & - & 2 & - & - & 2 \\
\hline Luciosomatrinema & seluangjuo & - & & 3 & - & 3 \\
\hline Macrochirichthysmacrochirus & parang-parangbengkok & - & 2 & 1 & - & 3 \\
\hline Malayochelamaassi & seluangpipih & - & 1 & 3 & - & 4 \\
\hline Osteochiluskappeni & aropadi & - & - & - & 1 & 1 \\
\hline Osteochilusmelanopleura & Kujam & - & - & 1 & - & 1 \\
\hline Osteochilusspirulus & Kujam & - & - & 1 & - & 1 \\
\hline Osteochilustriporos & Kujam & - & 3 & 1 & 2 & 6 \\
\hline Osteochiluswandersii & Kujam & - & - & - & 4 & 4 \\
\hline
\end{tabular}




\begin{tabular}{|c|c|c|c|c|c|c|}
\hline Oxygasteranomalura & Seluang ping-ping & - & 2 & 2 & - & 4 \\
\hline Parachelahypopthalmus & amis-amis & - & 41 & - & - & 41 \\
\hline Parachelaoxygastroides & amis-amis & - & - & 2 & - & 2 \\
\hline Puntigrustetrazona & aji-aji & 5 & - & 7 & - & 12 \\
\hline Puntiuslineatus & seluangkuring & 1 & 4 & 3 & 2 & 10 \\
\hline Rasborabankanensis & Seluang & - & - & - & 6 & 6 \\
\hline Rasboracaudimaculata & Seluang & - & - & - & 1 & 1 \\
\hline Rasbora cf. sumatrana & Seluang & - & - & - & 1 & 1 \\
\hline Rasboradusonensis & Seluang & 50 & 3 & 16 & 2 & 71 \\
\hline Rasboraelegans & Seluang & - & - & - & 3 & 3 \\
\hline Rasborasumatrana & Seluang & - & - & - & 8 & 8 \\
\hline Rasboratrilineata & Seluang & 10 & & 14 & - & 24 \\
\hline Thynnichthysthynnoides & Damaian & - & 57 & - & - & 57 \\
\hline Oxyeleotrismarmorata & Betutu & - & - & - & - & 0 \\
\hline Helostoma temminckii & Tembakang & - & - & 4 & - & 4 \\
\hline Mastacembeluserythrotaenia & tilanapi & - & - & 1 & - & 1 \\
\hline Nandusnebulosus & kerapurawa & 2 & - & - & 1 & 3 \\
\hline Nemacheilusfasciatus & Tali-tali & - & 2 & 8 & - & 10 \\
\hline Nemacheiluskapuasensis & Tali-tali & 1 & & 1 & - & 2 \\
\hline Trichopodusleerii & Sepat & - & 7 & 2 & - & 9 \\
\hline Pristolepisgrootii & Sepatung & - & & 1 & - & 1 \\
\hline Pseudeutropiusmoolenburghae & riu-riu & - & 1 & 1 & - & 2 \\
\hline Kryptopteruslimpok & lais & - & - & - & 2 & 2 \\
\hline Kryptopterusmacrocephalus & lais & - & - & - & 2 & 2 \\
\hline Kryptopterus sp. & lais & - & - & 1 & - & 1 \\
\hline Ompokeugeneiatus & laisbengkok & - & 5 & 8 & - & 13 \\
\hline Hippichthysspicifer & tangkur & - & - & - & 1 & 1 \\
\hline Hemirhamphodontengah & julung-julung & 1 & - & - & 3 & 4 \\
\hline Zenarchopterusdispar & julung-julung & - & - & - & 1 & 1 \\
\hline Jumlah & 71 & 151 & 111 & 42 & 375 & \\
\hline
\end{tabular}

Dari Tabel 4 menunjukan bahwa stasiun 2 (Putusan Marihot) ditemukan paling banyak jumlah ikan 151 ekor, diiukuti stasin 3 (Lubuk Kapas) 111 ekor, stasiun 3 (Muara Bato) 71 ekor dan Stasiun 4 ( Lubuk Bato ) 42 ekor. Jumlah spesies setiap stasiun 1 (8 spesies), Stasiun 2 (16 spesies), (29 spesies), stasiun 4 ( 18 spesies). Spesies yang ditemukan di semua stasiun meliputi Rasbora dusonensis, Puntius lineatus.

Berdasarkan informasi dari masyarakat yang beraktivtas di sekitar Sungai Kaps, bahwa sekitar satu miggu sebelum surva, areal sungai Kapas sudah di racun oleh masyarakat dan ini pada saat survai masih ditemukan bekas bekas bangkai ikan yang berada di pasir dan beberapa sudah tinggal tulang. Pada saat survai kondisi air belum pulih karena belum ada hujan dan hal ini sangat berpengaruh terhadap hasil tangkapan. Stasiun 3 ditemukan spesies paling banyak karena merupakan refuge area yang berada di Sungai utama dan banyak ditemukan batang kayu mati kemungkinan dimanfaatkan ikan untuk areal persembunyian. Stasoin 4 (Lubuk Bato) paling sedikit karena sungai Bato telatif kering saat musim kemaraub dan beberapa bagian sungai bisa dilewati. Areal lubuk Bato juga sangat kecil dengan kebar sekitra $6 \mathrm{~m}$ dan panjnag $10 \mathrm{~m}$. Untuk membuat program aplkasi FGo Iwak, setiap spesies selanjutnya di deskripsikan dan di soukmentasikan dalam keadaan hidup dan mati. 


\section{CONCLUTION}

Hasil Penelitian di refuge Sungai Kapas Tengah, melputi 50 spesies, 29 genus, dan 14 famili, serta 6 ordo. Pada stasiun 2 (Putusan Marihot) ditemukan paling banyak jumlah ikan 151 ekor, diiukuti stasin 3 (Lubuk Kapas) 111 ekor, stasiun 3 (Muara Bato) 71 ekor dan Stasiun 4 ( Lubuk Bato ) 42 ekor. Jumlah spesies setiap stasiun 1 (8 spesies), Stasiun 2 (16 spesies), (29 spesies), stasiun ( 18 spesies).

\section{ACKNOWLEGMENT}

Penelitian ini dibiayai dana BNPT Faklutas Sain dan Teknologi Unversitas Jambi, maka dengan selesainya penelitian ini kami mengucapakn terimakasih kepada Univetrsitas Jambi khususnya Dekan FST yang telah membiayai riset ini. Ucapan terima kasioh juga kami sampaikan kepada PT REKI-Hutan Harapan yang telah menberi dukungan sarana dan prasarana selama pengambilan sampel di Sungau Kapas dan Camp Bato

\section{REFERENCES}

Balza A, Kartika F. 2005. Teknik Pengolahan Citra Digital Menggunakan Delphi. Ardi Publishing, Yogyakarta.

[Fish Base ] 2017 A Global Information System on Fishes. World Fish Centre.www, fisbase.org

Kottelat M, Whitten AJ, Kartikasari SN, Wirjoatmojo S. 1993. The Freshwater Fishes of western Indonesia and Sulawesi. Periplus Edition \& EMDI Project.Jakarta. 293 p.

Kottelat M and Whitten AJ. 2009. The fishes of Batanghari drainage, Sumatra with description of six new species J. for Field-Oriented ichtyology 20:1-96

[REKI] Restorasi Ekosistem Indonesia. 2008. Harapan Rainforest Sumatra. Bogor P. 6

Sukmono T, Duryadi D, Rahardjo MF, Affandi R. 2013. Iktiofauna di perairan hutan tropis dataran rendah, Hutan Harapan Jambi. Jurnal Iktiologi Indonesia.13(2): 161-174.

Sukmono T dan Margaretha M. 2017. Ikan Air Tawar di Ekosistem Bukit Tigapuluh. Yayasan Konservasi Ekosistem Hutan Sumatra dan Frankfurt Zoological Society. 